\title{
Endophytic Fungi from Alstonia boonei De Wild and Greenwayodendron suaveolens (Engl. and Diels) Verdc. subsp. Suaveolens Possess Inhibitory Activity against Pneumonia Causing Bacteria
}

\author{
Paola Cynthia Emoh Demeni $\mathbb{D}^{1},{ }^{1}$ Patrick Hervé Diboue Betote $\mathbb{D}^{1,},{ }^{1,2,3}$ \\ Christelle Wayoue Kom, ${ }^{2}$ Eric Ngalani Tchamgoue, ${ }^{1}$ Esther Del Florence Ndedi Moni $\mathbb{D}^{1}$ \\ Jacqueline Saurelle Foumane Maniepi, ${ }^{3}$ Gabriel A. Agbor ${ }^{(D)}{ }^{2}$ \\ and Maximilienne Ascension Nyegue $\mathbb{D}^{1,4}$
}

${ }^{1}$ Laboratory of Microbiology, Department of Microbiology, Faculty of Science, University of Yaoundé I, P.O. Box 812, Yaoundé, Cameroon

${ }^{2}$ Laboratory of Pharmacology, Centre for Research on Medicinal Plants and Traditional Medicine, Institute of Medical Research and Medicinal Plants Studies, P.O. Box 13033, Yaoundé, Cameroon

${ }^{3}$ Multidisciplinary Laboratory, Department of Galenical Pharmacy and Pharmaceutical Law, Faculty of Medicine and Biomedical Sciences, University of Yaoundé I, Yaoundé, Cameroon

${ }^{4}$ Equipe Glyco et Nanovecteurs Pour le Ciblage Thérapeutique, Université of Montpellier, IBMM UMR 5247 CNRS-UM. 15 Avenue Charles Flahault, BP 14491, FR-34093 Montpellier Cedex 5, France

Correspondence should be addressed to Maximilienne Ascension Nyegue; maxy_nyegue@yahoo.fr

Received 23 March 2021; Accepted 28 July 2021; Published 5 August 2021

Academic Editor: Smail Aazza

Copyright (c) 2021 Paola Cynthia Emoh Demeni et al. This is an open access article distributed under the Creative Commons Attribution License, which permits unrestricted use, distribution, and reproduction in any medium, provided the original work is properly cited.

This study evaluated the antibacterial efficacy of methanolic extracts of isolated endophytic fungi from stem barks and leaves of Alstonia boonei De Wild and Greenwayodendron suaveolens (Engl. and Diels) Verdc. subsp. Suaveolens against Klebsiella pneumoniae ATCC 43816, Haemophilus influenzae ATCC 49247, Pseudomonas aeruginosa ATCC 27853, and Escherichia coli ATCC 35218, responsible for causing pneumonia. The endophytic fungi were isolated and characterized in the Potato Dextrose Agar (PDA), Sabouraud Dextrose Agar (SDA), and Czapek Dox Agar (CDA) media. The fungi and their methanolic extracts were tested for in vitro antibacterial potential by antagonistic assay for endophytic fungi against bacterial pathogens and microdilution method. The phytochemical screening of extracts was carried out according to the colorimetric and precipitation methods to reveal the presence of secondary metabolites. The results showed that 24 macroscopically and microscopically distinct endophytic fungi were isolated, identified, and stored. These endophytic fungi possessed antibacterial activity against the selected bacterial strains with inhibition zones ranging from 7.00 to $25.00 \mathrm{~mm}$. The endophytic fungi $\mathrm{GS}_{15}$ and $\mathrm{AB}_{24}$ have presented the inhibitions zones of $20.33 \mathrm{~mm}$ and $25.00 \mathrm{~mm}$, respectively, and these were better than the ones obtained for Levofloxacin ${ }^{\circledR}$. The endophytes with inhibition zones greater than $10 \mathrm{~mm}$ were used for extraction of their secondary metabolites. The endophytic fungi extracts showed antibacterial activity with the minimum inhibitory concentrations (MICs) ranging from $6.25 \times 10^{-4}$ to $2 \times 10^{-2} \mathrm{~g} / \mathrm{L}$ and the minimum bactericidal concentrations (MBCs) ranging from $2.5 \times 10^{-3}$ to $2 \times 10^{-2} \mathrm{~g} / \mathrm{L}$. The endophytic fungi GS $\mathrm{G}_{15}$ extract was the most effective extract; it showed bactericidal effects on the tested bacterial strains. The phytochemical screening of the extracts revealed the presence of secondary metabolites classes, responsible for causing the obtained antibacterial activity. Thus, the endophytic fungi methanolic extracts from A. boonei and G. suaveolens have the potential to inhibit the growth of bacteria responsible for nosocomial pneumonia. 


\section{Introduction}

Pneumonia is a lower respiratory tract infection caused by several infectious agents, including viruses, bacteria, and fungi [1]. However, pneumonia caused by bacterial infection has a rapidly progressive clinical course, which often becomes complicated by inflammation of the lungs, multilobular involvement, and lung abscesses $[2,3]$. As the third deadliest infectious disease worldwide after tuberculosis and hepatitis B, it is also the leading cause of infectious deaths in children worldwide, but it is most prevalent in South Asia and sub-Saharan Africa. It accounted for 922,136 and 808,694 deaths in children below the age of five years in 2015 and 2017, respectively, representing up to $15 \%$ of all deaths of children below five years of age [4]. Hence, the pneumonia causing bacteria represents the leading cause of infant morbidity and mortality recorded in low-income countries [5] accounting for $16.5 \%$ deaths among children aged 0 to 59 months in Cameroon $[6,7]$. In France, pneumonia is also responsible for $30 \%$ of deaths among adults over the age of 65 years. Appropriate antibiotic therapy involves Amoxicillin ${ }^{\circledR} /$ Clavulanic $^{\circledR}$ acid and Levofloxacin ${ }^{\circledR}$ for patients with pneumonia [8]. However, this treatment is relatively expensive in low-income countries; meanwhile, the pneumonia causing Gram-negative bacteria is responsible for microbial resistance [9]. Therefore, this scenario necessitates exploration of the various possibilities for treatment of this disease [10]. Different therapeutic strategies have already been implemented for treatment of this disease; among which use of medicinal plants offers an inexhaustible source of drugs [11].

Alstonia boonei De Wild belongs to the Apocynaceae family. About 110 species of this genus grow alongside the American tropical region. Preparations using the leaves, seeds, stem barks, and roots of different plants from the Apocynaceae family have been largely used in traditional medicine and some plants of Alstonia genus have been widely used as a febrifuge to treat malaria and other skin problems. Alcoholic extracts of the stem barks of A. boonei (to a lesser degree of the leaf) showed a broad-spectrum activity against both Gram-negative and Gram-positive bacteria, as well as fungi [12].

According to Lissambou et al., Greenwayodendron suaveolens (Engl. and Diels) belonging to the Annonaceae family has long been used as food and herbal medicine in Central Africa, especially as powdered supplement [13]. The genus Greenwayodendron is traditionally used for its antimalarial, antimenorrhagic, and antidysenteric properties [14]. This genus is a rich source of biologically active secondary metabolites with antimicrobial $[15,16]$, analgesic [17], antimalarial [18], and anthelminthic [19] activities.

For centuries, plants have served as medicinal bioactive compounds source against many forms of disease. In contrast, during the last few years, microorganisms associated with plants rather than the plants themselves have been shown to offer products with high therapeutic potential [20]. All microorganisms (bacteria and fungi) that inhabit asymptomatically, at least for one period of their life cycle, the internal plant tissues beneath the epidermal cell layers may be considered as endophytes [21]. Their role is to improve plant's access to nutrients and produce special substances, mainly secondary metabolites and enzymes which are responsible for plant adaptation to abiotic stress [22]. During the long coevolution of endophytes and their host plants, endophytes have adapted themselves to their special microenvironments by genetic variation, including uptake of some plant DNA into their own genomes. This could have led to the ability of certain endophytes to biosynthesize some "phytochemicals" originally associated with the host plants [23]. Of the endophytic microorganisms, fungi have been isolated the most [24] as they have been proved to be the promising sources of biologically active products with antioxidant, immunosuppressive, antiproliferative, anti-inflammatory [23], and antibacterial activities [25]. Furthermore, considering the exponential evolution of antibiotic resistance in human pathogens in recent years, it has become inevitable to search for more efficacious antibiotics. Thus, the antimicrobial activities have been evaluated for a variety of metabolites biosynthesized by endophytic fungi $[10,24]$ and there is an increasing effort to characterize, identify, and evaluate the potential biological effects of endophytic fungal extracts isolated from medicinal plants [21]. However, the endophytes of $A$. boonei and $G$. suaveolens have not yet been characterized.

The present study evaluated the antibacterial potential of the methanolic extracts of endophytic fungi of stem barks and leaves of Alstonia boonei De Wild and stem barks of Greenwayodendron suaveolens (Engl. \& Diels) Verdc. subsp. Suaveolens on the growth of several bacterial strains responsible for nosocomial pneumonia.

\section{Material and Methods}

2.1. Plant Materials. Healthy and mature plants without any visual disease symptom were carefully chosen for sampling. Leaves and stem barks of $A$. boonei were harvested from the botanical garden of the Institute of Medical Research and Medicinal Plants Studies, Yaoundé, Cameroon (Lat. $3^{\circ} 51^{\prime}$ $39.298^{\prime \prime} \mathrm{N}$; Long. $11^{\circ} 30^{\prime} 19.192^{\prime \prime} \mathrm{E}$ ) in the month of November 2018 and the stem barks of $G$. suaveolens were harvested in February 2019 at Mount Kala (Lat. $3^{\circ} 52^{\prime}$ $28.515^{\prime \prime} \mathrm{N}$; Long. $11^{\circ} 27^{\prime} 9.335^{\prime \prime} \mathrm{E}$ ) in Nkolbisson locality in Yaoundé, Cameroon. A. boonei and G. suaveolens samples were identified at the Cameroon National Herbarium under identification no. 43365/HNC and identification no. 45578 / HNC, respectively.

2.2. Isolation and Cultivation of Endophytic Fungi. The plant samples were washed under running tap water, and sterilization of leaves surfaces was achieved by subsequently soaking them in a series of solutions as follows: sterile distilled water for $2 \mathrm{~min}$, ethanol $70 \%$ for $2.5 \mathrm{~min}$, sodium hypochlorite $2.4 \%$ for $4 \mathrm{~min}$, and ethanol $70 \%$ for $1 \mathrm{~min}$, and 
finally they were rinsed with sterile distilled water for 3 times $[26,27]$. They were dried in sterile absorbent paper. The last washing water was plated on Petri dishes containing Potato Dextrose Agar (PDA). The success of surface sterilization method was confirmed by the absence of any microbial growth on the culture media plated with the last washing water. The sterilized leaves were cut into $5 \mathrm{~mm}$ segments using a sterilized knife. Ten parts of each plant segments were placed in Petri dishes $(9 \mathrm{~cm})$ containing PDA supplemented by $0.5 \%$ of chloramphenicol and incubated at $28 \pm 2^{\circ} \mathrm{C}$ [26]. Regular observations were carried out from the second day onwards for a period of 3 to 4 weeks for fungal growth. The fungal growth from internal tissues was checked for purity and transferred to fresh culture slants and then stored at $4^{\circ} \mathrm{C}$ for further study [27].

2.3. Identification of Endophytic Fungi. Identification of endophytic fungi associated with leaves or stem barks segments of plants was done based on their morphological and taxonomic properties (macroscopically and microscopically) on PDA, Sabouraud Dextrose Agar (SDA), and Czapek Dox Agar (CDA) media at $28 \pm 2^{\circ} \mathrm{C}$ [28-34]. The macroscopic characteristics observed were color and surface colonies (granular, such as flour, mounting, slippery), texture, zonation, growth area, the lines of radial and concentric, reverse color, and exudate drops. The microscopic examinations of the vegetative thallus, fruiting bodies, and spores were carried out with methylene blue and Congo red reagents. The species identification was done according to the methods described earlier [35-38].

\subsection{Extraction of Secondary Metabolites of Endophytic Fungi}

2.4.1. Fermentation. Four endophytic fungi previously purified with inhibition zones higher than $10 \mathrm{~mm}$ on the tested bacteria were chosen for this purpose. Thus, some mycelial agar plugs from these endophytic fungi culture were cultivated into $500 \mathrm{~mL}$ culture flask containing 250 grams of sterile rice. The culture was incubated at still condition at room temperature under dark condition for 3 to 4 weeks [39].

2.4.2. Extraction of Endophytic Fungal Culture. After incubation period, biomass and culture media were extracted with methanol. The methanolic fraction was evaporated under reduced pressure by Heidolph brand rotary evaporator.

\subsection{Assessment of Antibacterial Activity}

2.5.1. Bacterial Strains. The antibacterial activities were tested using qualitative biological analysis in triplicate. The pathogenic bacteria used in this study were Haemophilus influenza ATCC 49247, Pseudomonas aeruginosa ATCC 27853, Escherichia coli ATCC 35218, and Klebsiella pneumoniae ATCC 43816. These bacterial strains were provided by the Laboratory of Bacteriology of Yaoundé University Hospital Centre (Cameroon).

2.5.2. Antagonistic Assay for Endophytic Fungi against Bacterial Pathogens. Antagonistic activities of twenty-four endophytic fungi were tested for their antibacterial activity [40]. The test bacteria grown on liquid Mueller-Hinton medium for $24 \mathrm{~h}$; the concentration was adjusted at $1 \times 10^{6}$ cells $/ \mathrm{mL}$ [41]. The bacteria $(100 \mu \mathrm{L})$ were inoculated on the Petri dishes containing solid Mueller-Hinton medium. Afterwards, the disks of agar $(\varnothing 6 \mathrm{~mm})$ of each endophytic fungus young strain ( 5 to 7 days) were inoculated and placed at equidistant. The plates remained incubated at $37 \pm 2^{\circ} \mathrm{C}$ for $24 \mathrm{~h}$. Levofloxacin ${ }^{\circledR}$ (Sigma) $(100 \mu \mathrm{g} / \mathrm{mL}$ in dimethyl sulfoxide $(4 \% ; \mathrm{v} / \mathrm{v}))$ was employed as positive control. All the experiments were carried out using a completely randomized design (CRD), with three repetitions [42].

The presence of zone clearance on agar plates was used as an indicator for the antibacterial activity of endophytic fungi under investigation. The strains, which showed the maximum zone of clearance, were chosen for further study. The presence of these inhibition zones on agar plates was used as indicator of bioactive potential of endophytic fungi strains $[43,44]$.

\subsubsection{Microdilution Assay of Endophytic Fungi Extracts}

(1) Determination of Minimum Inhibitory Concentration (MIC). The geometric serial broth microdilution method was carried out according to the Microplate Alamar Blue Assay (MABA) described previously by the Clinical and Laboratory Standards Institute. A stock solution was prepared by diluting the respective sample in dimethyl sulfoxide (4\%; v/v). Stock solution was then added to Mueller-Hinton broth to reach final samples concentrations ranging from $2 \times 10^{-2} \mathrm{~g} / \mathrm{L}$ to $1.95 \times 10^{-5} \mathrm{~g} / \mathrm{L}$. Bacterial inocula $\left(1.5 \times 10^{8} \mathrm{CFU} / \mathrm{mL}\right)$ were added to each dilution. Each 96well microtiter plate was incubated at $37^{\circ} \mathrm{C}$ for $24 \mathrm{~h}$. Positive control consisted of Levofloxacin ${ }^{\circledR}$ at $2.5 \times 10^{-4} \mathrm{~g} / \mathrm{L}$, negative control contained no drugs, and blank contained neither inoculum nor drug. The concentration of dimethyl sulfoxide in the assay was kept at $5 \%$ to ensure that its effect on bacterial growth can be maintained as minimal. Upon incubation periods, $40 \mu \mathrm{L}$ of $0.02 \%$ resazurin was added to individual wells and the plates were reincubated for additional $30 \mathrm{~min}$ and checked for color change. Change in resazurin color from blue to pink indicated reduction of the indicator due to bacterial growth. The MIC was defined as the lowest concentration of samples at which the microorganisms did not demonstrate growth [45].

(2) Determination of Bactericidal Effect. The Minimal Bactericidal Concentrations (MBC) of promising methanolic extracts of endophytic fungi were assessed by subculturing MIC test microtiter plates on Mueller-Hinton medium. The MBC was considered as highest dilution or lowest concentration at which no growth occurred in the medium. All the experiments were done in triplicate [45]. 
The antibacterial effect was deemed bactericidal or bacteriostatic depending on the ratio of MBC to MIC. If $\mathrm{MBC} / \mathrm{MIC}$ is lower than four, the antibacterial effect of endophytic fungi extracts is bactericidal and bacteriostatic when MBC/MIC was higher than four [46].

2.6. Phytochemical Screening of Endophytic Fungi Extracts. Preliminary phytochemical screening of secondary metabolites of methanolic extracts of endophytic fungi was carried out according to methods described by Harborne and Evans $[47,48]$.

2.7. Statistical Analysis. All experiments for antagonistic assays were conducted in triplicate and values of inhibition zones expressed in $\mathrm{mm}$ as the mean $\pm \mathrm{SD}$. Variations in means were analyzed using one-way analysis of variance (ANOVA) and means were statistically significant if $p<0.05$.

\section{Results}

3.1. Isolation and Identification of Endophytic Fungi. A total of 83 endophytic fungi were isolated from $A$. boonei and $G$. suaveolens and grouped into 24 fungi isolates. It was found that 16 fungi isolates were identified, belonging to four different genera: Aspergillus (12.5\%), Fusarium (37.5\%), Neoscytalidium (8.33\%), and Acremonium (8.33\%). These genera belong to Deuteromycota division, more precisely to the Hyphomycetes class. They were divided into hyaline hyphomycetes (Moniliaceae order) with Aspergillus spp., Fusarium spp., Acremonium spp., and dark hyphomycetes (Dematiaceae order) with the only genus Neoscytalidium spp. being identified. However, the remaining 08 endophytic fungi could not be identified due to their issues related infertility (Table 1).

Some morphological and microscopical characteristics of isolated endophytic fungi are represented in Figure 1.

Isolates of the genus Aspergillus appeared with bright colors, which made their identification easy. Three species of this genus were identified in this study. The mycelial colonies of the isolated species are either powdery with black color (Aspergillus sp. 1) and green in PDA and SDA media but orange-yellow in CDA medium (Aspergillus sp. 3) or downy with black color in PDA and white in CDA and SDA media (Aspergillus sp. 2). These isolates were also characterized by a septate thallus and an unbranched conidiophore with varying lengths and shapes, ending in a bulge or vesicle bearing phialides or sometimes separated by metules, which is characteristic of the genus called Aspergillus head.

The colonies of isolates of the Fusarium genus were downy or cottony with different colors ranging from pinkish white for Fusarium sp. 1 and 2 to brown in PDA for Fusarium sp. 3 with other colors such as pink or yellow for Fusarium spp. 4, 7, 8, and 9, especially in SDA and CDA media. Microscopy presented septate vegetative thallus with cluster or chain arrangement of microconidia, fusiform macroconidia, curved and quite pointed at the
TABle 1: Summary of endophytic fungi isolated from Alstonia boonei and Greenwayodendron suaveolens.

\begin{tabular}{|c|c|c|c|c|}
\hline No. & Codes & Sources & Host plant & Genera names \\
\hline 01 & $\mathrm{GS}_{15}$ & Stem bark & G. suaveolens & Aspergillus sp. 1 \\
\hline 02 & $\mathrm{GS}_{81}$ & Stem bark & G. suaveolens & Aspergillus sp. 2 \\
\hline 03 & $\mathrm{AB}_{58}$ & Stem bark & A. boonei & Aspergillus sp. 3 \\
\hline 04 & $\mathrm{ab}_{24}$ & Stem bark & A. boonei & Fusarium sp. 1 \\
\hline 05 & $\mathrm{ab}_{17}$ & Stem bark & A. boonei & Fusarium sp. 2 \\
\hline 06 & $\mathrm{ab}_{34}$ & Stem bark & A. boonei & Fusarium sp. 3 \\
\hline 07 & $a_{46}$ & Stem bark & A. boonei & Fusarium sp. 4 \\
\hline 08 & $\mathrm{ab}_{50}$ & Leave & A. boonei & Fusarium sp. 5 \\
\hline 09 & $a b_{59}$ & Stem bark & A. boonei & Fusarium sp. 6 \\
\hline 10 & $a_{57}$ & Stem bark & A. boonei & Fusarium sp. 7 \\
\hline 11 & $a b_{80}$ & Stem bark & A. boonei & Fusarium sp. 8 \\
\hline 12 & $\mathrm{ab}_{47}$ & Leave & A. boonei & Fusarium sp. 9 \\
\hline 13 & $a b_{77}$ & Stem bark & A. boonei & Acremonium sp. 1 \\
\hline 14 & $a b_{83}$ & Leave & A. boonei & Acremonium sp. 2 \\
\hline 15 & $\mathrm{ab}_{45}$ & Leave & A. boonei & Neoscytalidium sp. 1 \\
\hline 16 & $\mathrm{ab}_{38}$ & Stem bark & A. boonei & Neoscytalidium sp. 2 \\
\hline 17 & $\mathrm{ab}_{21}$ & Stem bark & A. boonei & Not identified 1 \\
\hline 18 & $\mathrm{ab}_{33}$ & Stem bark & A. boonei & Not identified 2 \\
\hline 19 & $\mathrm{ab}_{36}$ & Leave & A. boonei & Not identified 3 \\
\hline 20 & $a_{65}$ & Leave & A. boonei & Not identified 4 \\
\hline 21 & $a_{23}$ & Stem bark & A. boonei & Not identified 5 \\
\hline 22 & $a_{69}$ & Stem bark & A. boonei & Not identified 6 \\
\hline 23 & $a b_{78}$ & Stem bark & A. boonei & Not identified 7 \\
\hline 24 & $a b_{72}$ & Leave & A. boonei & Not identified 8 \\
\hline
\end{tabular}

AB: Alstonia boonei; GS: Greenwayodendron suaveolens.

tips of the phialides, and the early presence of chlamydospores as seen on Fusarium sp. 2, justifying their belonging to the Fusarium genus. The colonies of isolates of the Acremonium genus were woolly in SDA and CDA and very poor in filaments or even hairless in PDA. Different colors were obtained like white and pink in SDA medium with a slow growth rate for Acremonium sp. 2 and a rapid growth rate for Acremonium sp. 1, as well as milkywhite and white in PDA and CDA media. Microscopy presented a vegetative thallus made up of septate filaments, fine, cylindrical phialides at their tips, and cylindrical conidia grouped together in clusters. The colonies produced by the genus Neoscytalidium were milky-white fluffy in PDA and CDA media or woolly beige for Neoscytalidium sp. 2 and hairless brown for Neoscytalidium sp. 1 in SDA media. Microscopically, the hyphae are septate and hyaline; others are larger and strongly pigmented dissociating into arthroconidia. However, fungi isolates such as 17,18 , and 19 were unidentified as they did not produce sporing structures on PDA, SDA, and CDA media but presented dirty white cotton growth that darkened with age differently in each isolate. Microscopy presented septate and dark hyphae in fungi 17 and 18 differently from fungus 19 , which presented septate and hyaline hyphae.

3.2. Antagonistic Potential of Endophytic Fungi. In this investigation, four endophytic fungi $\left(\mathrm{GS}_{15}, \mathrm{AB}_{24}, \mathrm{AB}_{38}\right.$, and $\mathrm{AB}_{83}$ ) were selected for determination of inhibition parameters (MIC and $\mathrm{MBC}$ ) after testing the 24 fungi isolates 


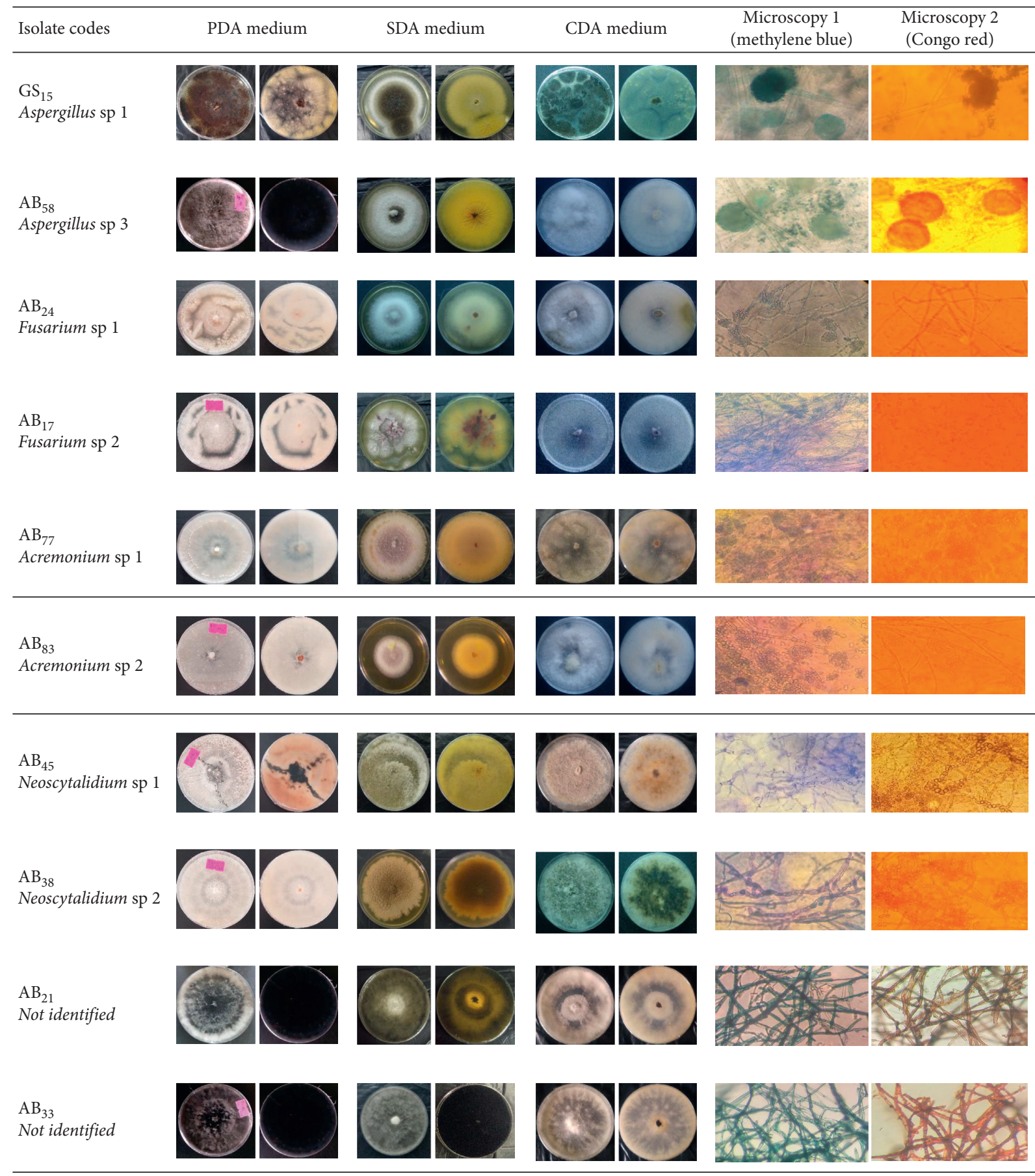

Figure 1: Morphology and microscopic characters of endophytic fungi isolated from Alstonia boonei and Greenwayodendron suaveolens.

from $A$. boonei and $G$. suaveolens on the growth of H. influenza, P. aeruginosa, E. coli, and K. pneumoniae. These fungi isolates $\left(\mathrm{GS}_{15}, \mathrm{AB}_{24}, \mathrm{AB}_{38}\right.$, and $\left.\mathrm{AB}_{83}\right)$ presented an antibacterial activity, with the inhibition zones ranging from $10.33 \pm 0.57 \mathrm{~mm}$ against $E$. coli to $25.00 \pm 1.00 \mathrm{~mm}$ against $H$. influenza. This was the most sensitive bacteria compared to those selected endophytic fungi with inhibition zone ranging from $20.33 \pm 0.57 \mathrm{~mm}$ for $\mathrm{AB}_{24}$ to $25.00 \pm 1.00 \mathrm{~mm}$ for $\mathrm{GS}_{15}$; the data obtained was compared to Levofloxacin ${ }^{\circledR}$ with an inhibition zone of $19.05 \pm 0.82 \mathrm{~mm}$ as in Table 2.
3.3. Antibacterial Activity of Endophytic Fungi Extracts. The antibacterial activities of the methanolic extracts of endophytic fungi from $A$. boonei and $G$. suaveolens are presented in Table 3. The methanolic extracts presented antibacterial activity against $H$. influenza, $P$. aeruginosa, $E$. coli, and $K$. pneumoniae with MIC values of $6.25 \times 10^{-4}-2 \times 10^{-2} \mathrm{~g} / \mathrm{L}$. The $\mathrm{GS}_{15}$ methanolic extract of endophytic fungi from $G$. suaveolens had the highest antibacterial activity with the MIC values of $6.25 \times 10^{-4} \mathrm{~g} / \mathrm{L}$ (H. influenzae), $2.5 \times 10^{-3} \mathrm{~g} / \mathrm{L}(P$. aeruginosa $), 2.5 \times 10^{-3} \mathrm{~g} / \mathrm{L}$ (K. pneumoniae), and $5 \times 10^{-3} \mathrm{~g} / \mathrm{L}$ (E. coli). The $\mathrm{GS}_{15}$ 
TABLE 2: Inhibition zones produced by endophytic fungi isolates on the growth of K. pneumoniae, H. influenzae, P. aeruginosa, and E. coli.

\begin{tabular}{|c|c|c|c|c|}
\hline \multirow{2}{*}{ Endophytic fungi isolates } & \multicolumn{4}{|c|}{ Inhibition zones $(\mathrm{mm})$} \\
\hline & H. influenzae & K. pneumoniae & P. aeruginosa & E. coli \\
\hline $\mathrm{GS}_{15}$ & $20.33 \pm 1.52$ & $19.00 \pm 0.00$ & $15.33 \pm 0.57$ & $10.33 \pm 0.57$ \\
\hline $\mathrm{AB}_{17}$ & $22.66 \pm 0.57$ & $22.66 \pm 0.57$ & $7.00 \pm 0.00$ & $7.00 \pm 0.00$ \\
\hline $\mathrm{AB}_{21}$ & $21.00 \pm 1.00$ & $17.66 \pm 0.57$ & - & - \\
\hline $\mathrm{AB}_{23}$ & $24.66 \pm 0.57$ & $19.00 \pm 0.00$ & - & $8.33 \pm 0.57$ \\
\hline $\mathrm{AB}_{24}$ & $25.00 \pm 1.00$ & $23.00 \pm 0.00$ & $20.00 \pm 0.00$ & $19.00 \pm 0.00$ \\
\hline $\mathrm{AB}_{33}$ & - & - & - & - \\
\hline $\mathrm{AB}_{34}$ & $17.33 \pm 0.57$ & $18.00 \pm 0.00$ & $8.33 \pm 1.52$ & $8.00 \pm 0.00$ \\
\hline $\mathrm{AB}_{36}$ & $10.66 \pm 0.57$ & - & $7.00 \pm 0.00$ & - \\
\hline $\mathrm{AB}_{38}$ & $20.33 \pm 0.57$ & $18.66 \pm 0.57$ & $19.00 \pm 0.00$ & $13.00 \pm 1.00$ \\
\hline $\mathrm{AB}_{45}$ & $14.00 \pm 1.00$ & $15.33 \pm 1.52$ & - & $17.33 \pm 0.57$ \\
\hline $\mathrm{AB}_{46}$ & - & $14.66 \pm 1.52$ & $8.00 \pm 0.00$ & $19.33 \pm 0.57$ \\
\hline $\mathrm{AB}_{47}$ & $7.00 \pm 0.00$ & $15.33 \pm 1.15$ & - & $18.33 \pm 1.15$ \\
\hline $\mathrm{AB}_{50}$ & - & - & $18.66 \pm 1.52$ & - \\
\hline $\mathrm{AB}_{57}$ & $13.00 \pm 1.00$ & - & $11.00 \pm 1.00$ & $16.00 \pm 0.00$ \\
\hline $\mathrm{AB}_{58}$ & $9.33 \pm 0.57$ & - & - & - \\
\hline $\mathrm{AB}_{59}$ & - & $10.66 \pm 1.15$ & - & $18.66 \pm 0.57$ \\
\hline $\mathrm{AB}_{65}$ & - & $12.00 \pm 1.00$ & $9.00 \pm 0.00$ & $17.00 \pm 1.00$ \\
\hline $\mathrm{AB}_{69}$ & - & $9.66 \pm 0.57$ & - & $8.00 \pm 1.00$ \\
\hline $\mathrm{AB}_{72}$ & $21.33 \pm 1.15$ & - & - & $7.00 \pm 1.00$ \\
\hline $\mathrm{AB}_{77}$ & $18.00 \pm 1.00$ & - & $8.00 \pm 1.00$ & $10.33 \pm 0.57$ \\
\hline $\mathrm{AB}_{78}$ & $8.33 \pm 0.57$ & $18.00 \pm 0.57$ & $7.00 \pm 1.00$ & $9.00 \pm 1.00$ \\
\hline $\mathrm{AB}_{80}$ & $24.00 \pm 0.00$ & $21.00 \pm 1.00$ & $9.00 \pm 1.00$ & $7.00 \pm 0.00$ \\
\hline $\mathrm{GS}_{81}$ & $16.00 \pm 0.00$ & - & $18.00 \pm 1.00$ & $13.00 \pm 0.00$ \\
\hline $\mathrm{AB}_{83}$ & $23.33 \pm 0.57$ & $19.66 \pm 1.15$ & $15.00 \pm 1.00$ & $12.66 \pm 0.00$ \\
\hline Levofloxacin ${ }^{\circledR}$ & $19.05 \pm 0.82$ & $19.51 \pm 0.35$ & $27.57 \pm 6.74$ & $20.37 \pm 1.64$ \\
\hline
\end{tabular}

AB: Alstonia boonei; GS: Greenwayodendron suaveolens; -: not determined. Values are the means of three replicates \pm SD.

TABLE 3: Minimum inhibitory concentration (MIC) and minimum bactericidal concentration (MBC) for antibacterial activity of methanolic extracts of endophytic fungi from A. boonei and G. suaveolens against K. pneumoniae, H. influenzae, P. aeruginosa, and E. coli.

\begin{tabular}{|c|c|c|c|c|c|}
\hline \multirow{2}{*}{ Samples } & \multirow{2}{*}{ Bacterial strains } & \multicolumn{3}{|c|}{ Inhibition parameters $(\mathrm{g} / \mathrm{L})$} & \multirow{2}{*}{ Antibacterial effects } \\
\hline & & MIC & $\mathrm{MBC}$ & $\mathrm{MBC} / \mathrm{MIC}$ & \\
\hline \multirow{4}{*}{$\mathrm{GS}_{15}$} & H. influenzae & $6.25 \times 10^{-4}$ & $2.5 \times 10^{-3}$ & 4 & Bactericidal \\
\hline & P. aeruginosa & $2.5 \times 10^{-3}$ & $5 \times 10^{-3}$ & 2 & Bactericidal \\
\hline & K. pneumoniae & $2.5 \times 10^{-3}$ & $5 \times 10^{-3}$ & 2 & Bactericidal \\
\hline & E. coli & $5 \times 10^{-3}$ & $2 \times 10^{-2}$ & 4 & Bactericidal \\
\hline \multirow{4}{*}{$\mathrm{AB}_{24}$} & H. influenzae & $2 \times 10^{-2}$ & $>2 \times 10^{-2}$ & - & - \\
\hline & $P$. aeruginosa & $2 \times 10^{-2}$ & $>2 \times 10^{-2}$ & - & - \\
\hline & K. pneumoniae & $2 \times 10^{-2}$ & $>2 \times 10^{-2}$ & - & - \\
\hline & E. coli & $>2 \times 10^{-2}$ & - & - & - \\
\hline \multirow{4}{*}{$\mathrm{AB}_{38}$} & H. influenzae & $10^{-2}$ & $2 \times 10^{-2}$ & 2 & Bactericidal \\
\hline & P. aeruginosa & $10^{-2}$ & $>2 \times 10^{-2}$ & - & - \\
\hline & K. pneumoniae & $10^{-2}$ & $>2 \times 10^{-2}$ & - & - \\
\hline & E. coli & $2 \times 10^{-2}$ & $>2 \times 10^{-2}$ & - & - \\
\hline \multirow{4}{*}{$\mathrm{AB}_{83}$} & H. influenzae & $2 \times 10^{-2}$ & $>2 \times 10^{-2}$ & - & - \\
\hline & P. aeruginosa & $2 \times 10^{-2}$ & $>2 \times 10^{-2}$ & - & - \\
\hline & K. pneumoniae & $2 \times 10^{-2}$ & $>2 \times 10^{-2}$ & - & - \\
\hline & E. coli & $2 \times 10^{-2}$ & $>2 \times 10^{-2}$ & - & - \\
\hline \multirow{4}{*}{ Levofloxacin $^{\circledR}$} & H. influenzae & $78 \times 10^{-7}$ & $625 \times 10^{-7}$ & 8 & Bacteriostatic \\
\hline & P. aeruginosa & $25 \times 10^{-5}$ & $25 \times 10^{-5}$ & 1 & Bactericidal \\
\hline & K. pneumoniae & $>25 \times 10^{-5}$ & - & - & - \\
\hline & E. coli & $>25 \times 10^{-5}$ & - & - & - \\
\hline
\end{tabular}

AB: Alstonia boonei; GS: Greenwayodendron suaveolens; $\mathrm{GS}_{15}$ : methanolic extract of Aspergillus spp. 1; $\mathrm{AB}_{24}$ : methanolic extract of Fusarium spp. 1; $\mathrm{AB}_{38}$ : methanolic extract of Neoscytalidium spp. 2 and $\mathrm{AB}_{83}$ : methanolic extract of Acremonium spp. 2; —: not determined. 
methanolic extract is the only extract that presented a bactericidal effect on the growth of the four bacteria strains studied. $\mathrm{AB}_{38}$ also presented a bactericidal effect on $H$. influenzae compared to the bacteriostatic effect obtained for Levofloxacin ${ }^{\circledR}$ on the same bacteria.

3.4. Phytochemical Screening. The extracts of the selected endophytic fungi $\left(\mathrm{GS}_{15}, \mathrm{AB}_{24}, \mathrm{AB}_{38}\right.$, and $\left.\mathrm{AB}_{83}\right)$ have been used for several phytochemical tests to determine the presence of different types of bioactive compounds in them. The results presented in Table 4 indicated the presence of 10 secondary metabolites families in the methanolic extracts: alkaloids, phenols, polyphenols, tannins, saponins, flavonoids, anthocyanins, coumarins, terpenoids, and sterols. Unlike other classes of secondary metabolites that were ubiquitous to all four methanolic extracts, tannins were found exclusively in $\mathrm{AB}_{38}$ methanolic extract of $\mathrm{NeO}$ scytalidium sp. 2.

\section{Discussion}

4.1. Morphological and Microscopical Characterization. Isolation and identification of endophytic fungi have highlighted 4 genera, G. suaveolens (Aspergillus) and A. boonei (Aspergillus, Acremonium, Neoscytalidium, and Fusarium). The obtained results are similar to those of Abdel-Motaal et al. [49] who isolated endophytic fungi of Neoscytalidium, Aspergillus, Acremonium, and Fusarium genera from Hyoscyamus muticus, an Egyptian plant belonging to the Apocynaceae family same as $A$. boonei. In contrast, the study of Tolulope et al. [50] reported that the isolation of $A$. boonei endophytic fungi harvested in Nigeria contained three characterizing genera (Aspergillus, Microphoma, and Trichoderma). These results could therefore justify the hypothesis that endophytic fungi isolated from plants belonging to the same genus or family belong to the same genera. This is the case of A. scholaris and Hyoscyamus muticus according to the studies of Mahapatra and Banerjee and Abdel-Motaal et al., respectively, which indicated the presence of 19 genera with four similar genera (Neoscytalidium, Aspergillus, Acremonium, and Fusarium) in agreement with our study $[49,51]$. We noticed that the colonizing endophytic fungi from $A$. boonei and G. suaveolens in our study have low genera diversities.

In addition, the genus Fusarium was the predominant genus isolated from $A$. boonei and $G$. suaveolens with a frequency of $37.5 \%$. Indeed, it is one of the genera most associated with higher plants. Fusarium is among the most common fungi in terrestrial ecosystems. They are found in cultivated soils in temperate and tropical regions [37], and their predominance among the fungi isolated in this study corroborates with the study of Ilyas et al. [52] who explained that several fungi of the genus Fusarium were plant colonizers. In addition, $A$. boone $i$ was harvested in tropical areas, where soils are favorable for the growth of species of this genus.
TABLE 4: Phytochemical screening of the methanolic extracts of endophytic fungi $\left(\mathrm{GS}_{15}, \mathrm{AB}_{24}, \mathrm{AB}_{38}\right.$, and $\left.\mathrm{AB}_{83}\right)$.

\begin{tabular}{lcccc}
\hline \multirow{2}{*}{ Secondary metabolites } & \multicolumn{4}{c}{ Endophytic fungi extracts } \\
& $\mathrm{GS}_{15}$ & $\mathrm{AB}_{24}$ & $\mathrm{AB}_{38}$ & $\mathrm{AB}_{83}$ \\
\hline Alkaloids & +++ & ++ & + & + \\
Phenols & - & +++ & ++ & ++ \\
Polyphenols & ++ & + & + & + \\
Flavonoids & + & ++ & ++ & ++ \\
Tannins & - & - & + & - \\
Anthocyanins & - & + & + & + \\
Coumarins & ++ & + & - & ++ \\
Saponins & - & + & ++ & ++ \\
Terpenoids & +++ & + & + & + \\
Steroids & +++ & + & + & + \\
\hline
\end{tabular}

AB: Alstonia boonei; GS: Greenwayodendron suaveolens; $\mathrm{GS}_{15}$ : methanolic extract of Aspergillus sp. $1 ; \mathrm{AB}_{24}$ : methanolic extract of Fusarium sp. $1 ; \mathrm{AB}_{38}$ : methanolic extract of Neoscytalidium sp. 2 and $\mathrm{AB}_{83}$ : methanolic extract of Acremonium sp. 2.

\subsection{Antibacterial Activity of Endophytic Fungi Extracts}

4.2.1. Antagonistic Potential of Endophytic Fungi. The antagonistic potential of endophytic fungi $\left(\mathrm{GS}_{15}, \mathrm{AB}_{24}, \mathrm{AB}_{38}\right.$, and $\mathrm{AB}_{83}$ ) allowed obtaining clearance zones on agar plates against $H$. influenzae, $P$. aeruginosa, $K$. pneumoniae, and E. coli which are greater than $10.33 \mathrm{~mm}$ on the bacterial strains tested. The present inhibition justifies the antibacterial activity of these endophytic fungi strains on the bacteria responsible for pneumonia, which could be due to the presence of bioactive substances in the mycelial discs of these endophytic fungi [53]. However, other studies have shown that endophytic fungi isolated from plants could have antibacterial activity, so they would resist invasion and inhibit the bacteria inducing the diseases in humans through the production of inhibitory substances belonging to several structural classes like alkaloids, peptides, steroids, terpenoids, phenols, quinines, and flavonoids [24, 54, 55]. Our results corroborate with an earlier report in which the endophytic fungi studied belonged to Aspergillus, Acremonium, and Trichosporon genera isolated from Artemisia absinthium. These endophytic isolates showed antibacterial activity against $P$. aeruginosa ATCC27853 and E. coli ATCC25922 strains [56]. Although the tested strains responsible for pneumonia are naturally resistant due to their "Gram-negative" character, the obtained results show that the bioactive compounds secreted by these endophytic fungi would have the capacity to penetrate the external membranes surrounding the wall of Gram-negative bacteria made up of covering lipopolysaccharides by the phenomena of diffusion of lipophilic compounds. Another phenomenon, which could also explain the results obtained, is the diffusion of active substances on the agar, which depends on the nature of the diffusing substances excreted by the endophytic fungi, their concentrations, their solubility, and $\mathrm{pH}$ of the culture medium [57]. The high antibacterial activity revealed by endophytic fungi isolated from $A$. boonei and G. suaveolens is related to their ability to produce bioactive substances with medicinal properties [58]. 
4.2.2. Antibacterial Activity of Endophytic Fungi Extracts. The determination of the inhibition parameters (MIC and MBC) of methanolic extracts is shown by their MICs values of $6.25 \times 10^{-4}$ to $2 \times 10^{-2} \mathrm{~g} / \mathrm{L}$ for $H$. influenzae, $P$. aeruginosa, E. coli, and K. pneumonia strains. The highest antibacterial activity was obtained with the methanolic extract of Aspergillus sp. 1 that presented a bactericidal effect on all tested strains. This could be linked to a synergistic or additive effect of the secondary metabolites present in the methanolic extract. In addition, the mean bactericidal effect of this extract on the strains tested is in line with data reported by Amadi and Adeniyi, as well as those reported by Indira et al. $[59,60]$ who demonstrated the antimicrobial activity of the genus Aspergillus. The reduction mechanisms of bacteria or fungi growth of the Aspergillus genus (Aspergillus terreus, Aspergillus flavus, and Aspergillus fumigatus) endophytes may possess higher concentration of alkaloids (fumiclavin A and $\mathrm{B}$ and, fumigaclavin $\mathrm{B}$ ). In addition, most of these complex structures of fungi metabolites inhibit cell division and glucose transport $[59,61]$. The data obtained in the present study were different from those of Kalhouche and Meziane [62] showing the MIC value of Aspergillus sp. 1 extract against $E$. coli to be $100 \mathrm{mg} / \mathrm{mL}$. This difference may be because the Aspergillus strain used to inhibit the E. coli growth was not isolated from a medicinal plant. Hence, the production of secondary metabolites may not have been directed to any phytoprotective activity of plants. The methanolic extracts of $\mathrm{AB}_{24}, \mathrm{AB}_{38}$, and $\mathrm{AB}_{83}$ exhibited MICs ranging from $10^{-2}$ to $2 \times 10^{-2} \mathrm{~g} / \mathrm{L}$. Indeed, the phytochemical screening of these extracts revealed the presence of phenols, flavonoids, and coumarins whose antibacterial effect could have been inhibited or neutralized by other compounds present in these extracts at higher concentrations [63]. These bioactive secondary metabolites would have the ability to penetrate the lipopolysaccharides of the wall of the Gramnegative bacteria tested and inhibit their growth by mechanisms of action that allowed them to inactivate bacterial enzymes, modify the structure of the active site, and induce intracellular accumulation of bioactive metabolites [64]. The bioactive compounds found in the methanolic extracts of endophytic fungi of $A$. boonei and G. suaveolens are responsible for the antibacterial activity and may have a synergistic action [65].

\subsection{Phytochemical Screening of Endophytic Fungi Extracts.} The phytochemical screening of the methanolic extracts of endophytic fungi isolated from $A$. boonei and G. suaveolens has shown that all the extracts contain alkaloids, polyphenols, flavonoids, terpenes, and sterols. The presence of these secondary metabolites in the endophytic fungi could justify their antibacterial effect. Previous studies have shown that phytochemical compositions of $A$. boonei and G. suaveolens stem barks extracts were similar to those in the present study with the presence of alkaloids, phenols, polyphenols, flavonoids, anthocyanins, saponins, terpenoids, and sterols $[66,67]$.

These studies permitted highlighting the phytomolecular mimicry of endophytic fungi extract from $A$. boonei and
G. suaveolens. It appears that the phytochemical compositions of the endophytic fungi methanolic extracts of these plants would be similar to those of plant extracts $[66,67]$. Therefore, to verify this hypothesis, it would be necessary in a further study to make additional quantitative and qualitative analysis, especially molecular and genetic levels between endophytic fungi and the host plant.

\section{Conclusion}

In this study, the endophytic fungi from $A$. boonei and $G$. suaveolens exhibited antibacterial activity against some of the human pathogenic bacteria responsible for nosocomial pneumonia. This activity was greater in the methanolic extract of $\mathrm{GS}_{15}$ endophytic fungal isolated from G. suaveolens, a plant that has never been listed for its antipneumonic potential. The present study helped to valorize the use of endophytic fungi from $A$. boonei and G. suaveolens in drug discovery process. However, a molecular identification of isolated endophytic fungi from these plants is necessary for further investigations.

\section{Data Availability}

The datasets used and/or analyzed during the current study are available from the corresponding author upon reasonable request.

\section{Conflicts of Interest}

The authors declare that there are no conflicts of interest.

\section{Authors' Contributions}

P. C. E. D. participated in the isolation and characterization of endophytic fungi and revised the manuscript. P. H. D. B. initiated the project, participated in laboratory works analyzing the presence of secondary metabolites, isolation, and characterization of endophytic fungi and biological activities, and revised the manuscript. C. W. K. participated in the characterization of endophytic fungi and revision of the manuscript. E. N. T. participated in the isolation and characterization of endophytic fungi. E. D. F. N. M. participated in the characterization of endophytic fungi and revised the manuscript. J. S. F. M. participated in the characterization of endophytic fungi and revision of the manuscript. G. A. A. revised the manuscript. M. A. $\mathrm{N}$. initiated the project, guided the research work, and revised the manuscript. All authors read and approved the final version of the manuscript.

\section{Acknowledgments}

The authors are grateful to Professor (Dr.) Nnanga Nga for the antibacterial assays reagents, Professor (Dr.) Hortense Gonshu (Head of Laboratory for Bacteriology of Centre Hospitalier et Universitaire de Yaoundé) for providing the bacterial strains, and Dr. Tchokouaha Yamthe Laure Rachel and Dr. Tchamgoue Deutou Armelle for providing technical advice. 


\section{References}

[1] N.I.C.E (National Institute for Health and Care Excellence), "Pneumonia in adults: diagnosis and management," NICE Clinical Guideline, https://nice.org.uk/guidance/cg, p. 191, National Institute for Health and Care Excellence, London, UK, 2014, .

[2] S. J. Jay, "Nosocomial pneumonia," Postgraduate Medicine, vol. 74, no. 2, pp. 221-235, 1983.

[3] J. L. Carpenter, "Klebsiella pulmonary infections: occurrence at one medical center and review," Clinical Infectious Diseases, vol. 12, no. 4, pp. 672-682, 1990.

[4] W.H.O (World Health Organization), Global Pneumonia Report, World Health Organization, Geneva, Switzerland, 2019, https:// www.who.int/news-room/fact-sheets/detail/pneumonia.

[5] P. Aubry and B. A. Gaüzère, Généralités sur la Médecine Tropicale, Université de Bordeaux, Bordeaux, France, 2019, https://www.medecinetropicale.com.

[6] R. Wounang, S. Moluh, A. Koffi, H. Kalter, and P. Libite, Améliorer les Estimations des Causes et Facteurs qui Contribuent à la Mortalité Néonatale de l'enfant au CamerounEnquête d'autopsie Verbale/Sociale Dans les Districts de Nguelemendouka, Doume et Abong-Mbang, Etude Réalisée par l'Institut National de la Statistique, Bucharest, Romania, 2012.

[7] S. Gerard, Pneumopathies of the Elderly: Geriatric Capacity, Toulouse University Hospital, Toulouse, France, 2014, https:// www.medecine.ups-tlse.fr/capacite/geriatrie/Pneumopathies.

[8] A. S. Ouedraogo, H. Jean Pierre, A. L. Bañuls, R. Ouédraogo, and S. Godreuil, "Emergence and spread of antibiotic resistance in West Africa: contributing factors and threat assessment," Médecine et Santé Tropicales, vol. 27, no. 2, pp. 147-154, 2017.

[9] W.H.O (World Health Organization), "Working together for health: the world health report," WHO, Geneva, Switzerland, 2020, https://www.who.int/whr/2006/whr06_en.pdf?ua=1.

[10] G. Strobel and B. Daisy, "Bioprospecting for microbial endophytes and their natural products," Microbiology and Molecular Biology Reviews, vol. 67, no. 4, pp. 491-502, 2003.

[11] S. Handa, D. Rakesh, and K. Vasisht, "Compendium of medicinal and aromatic plants ASIA," Earth, Environmental and Marine Sciences and Technologies ICSUNIDO-AREA Science Park, vol. 6, p. 82, 2006.

[12] D. Louppe, A. A. Oteng-Amoako, and M. Brink, "Ressources végétales de l'Afrique tropicale," 2008.

[13] B. Lissambou, O. J. Hardy, C. Atteke et al., "Taxonomic revision of the african genus Greenwayodendron (Annonaceae)," PhytoKeys, vol. 114, pp. 55-93, 2018.

[14] H. M. Burkill, The Useful Plants of West Tropical Africa: Families $A-D$, Royal Botanical Gardens, Kew, Richmond, UK, 2nd edition, 1989.

[15] M. Idu, O. Ovuakporie-Uvo, N. O. Obayagbona, and O. Ogiemudia, "Phytochemistry, antimicrobial and toxicological studies of Greeenwayodendron suaveolens seed extracts," Journal of Basic Pharmacology and Toxicology, vol. 1, no. 1, pp. 8-12, 2017.

[16] T. R. B. Jiofack, "Greenwayodendron suaveolens (Engl. \& Diels) Verdc," in Timbers/Bois d'œuvre 2, R. H. M. J. Lemmens, D. Louppe, and A. A. Oteng-Amoako, Eds., PROTA, Wageningen, Netherlands, 2011.

[17] O. Timothy and S. Sobotie, "Analgesic activities and phytochemistry of aqueous leaf extract of Greenwayodendron suaveolens (Engl. and Diels) Verdc," Journal of Applied
Sciences and Environmental Management, vol. 23, no. 4, pp. 633-636, 2017.

[18] F. Ngoutane, M. Cedric, T. Lauve et al., "In vitro and in vivo antiplasmodial activity of extracts from Polyalthia suaveolens, Uvaria angolensis and Monodora tenuifolia (Annonaceae)," International Journal of Biological and Chemical Science, vol. 11, pp. 118-130, 2016.

[19] R. B. Tafokou, "Greenwayodendron suaveolens (Engl. \& Diels) Verdc," in Timbers/Bois d'ouvre 2, R. H. M. J. Lemmens, D. Louppe, and A. A. OtengAmoako, Eds., vol. 7, no. 2, PROTA, Wageningen, Netherlands, 2011.

[20] T. S. Suryanarayanan, N. Thirunavukkarasu, M. B. Govindarajulu, F. Sasse, R. Jansen, and T. S. Murali, "Fungal endophytes and bioprospecting," Fungal Biology Reviews, vol. 23, pp. 9-19, 2003.

[21] J. L. Azevedo, W. Maccheroni Jr., J. O. Pereira, and W. L. De Araújo, "Endophytic microorganisms: a review on insect control and recent advances on tropical plants," Electronic Journal of Biotechnology, vol. 3, no. 1, pp. 40-65, 2000.

[22] A. Selim, A. Elbeih, M. Abdel-Rahman, and I. El-Diwany, "Biology of endophytic fungi," International Journal of Pharmacology Science, vol. 5, pp. 889-897, 2012.

[23] H. Zhang, X. Bai, and B. Wu, "Evaluation of anti-microbial activities of extracts of endophytic fungi from Artemisia annua," Bangladesh Journal of Pharmacology, vol. 7, no. 2, pp. 120-123, 2012.

[24] G. Strobel, B. Daisy, U. Castillo, and J. Harper, "Natural products from endophytic microorganisms," Journal of Natural Products, vol. 67, no. 2, pp. 257-268, 2004.

[25] G. Molina, M. R. Pimentel, T. C. P. Bertucci, and G. M. Pastore, "Application of fungal endophytes in biotechnological processes," Chemical Engineering Transactions, vol. 27, pp. 289-294, 2012.

[26] T. Suryanarayanam, G. Venkatesan, and T. Murali, "Endophytic fungal communities in leaves of tropical forest treesDiversity and distribution patterns," Current Science, vol. 85, pp. 489-493, 2003.

[27] G. F. Bills and J. D. Polishook, "Microfungi from Carpinus caroliniana," Canadian Journal of Botany, vol. 69, no. 7, pp. 1477-1482, 1991.

[28] T. Kobayashi, Taxonomic Studies of Japanese Diaporthaceae with Special Reference to their Life Histories, Hokkaido University, Sapporo, Japan, 1970.

[29] M. B. Ellis, Dematiaceous Hyphomycetes, Commonwealth Mycological Institute, CMI (Kew), London, UK, 1971.

[30] K. H. Domsch, W. Gams, and H. T. Anderson, Compendium of Soil Fungi, Academic Press, London, UK, 1980.

[31] B. C. Sutton, The Coelomycetes. Fungi Imperfecti with Pycnidia, Acervuli and Stromata, CMI (Kew), London, UK, 1980.

[32] J. Webster, Introduction to Fungi, Cambridge University Press, Melbourne, Australia, 2nd edition, 1980.

[33] R. A. Samson, E. S. Hoekstra, J. C. Frisvad, and O. Filtenborg, Introduction to Food-Borne Fungi, Centraal Bureau Voor Schimmel Cultures, Baarn, Holland, 1995.

[34] H. L. Barnett and B. B. Hunter, Illustrated Genera of Imperfect Fungi, Prentice-Hall, New York, NY, USA, 4th edition, 1998.

[35] D. Malloch, La Détermination des Moisissures (Deutéromycètes), Department of Botany, University of Toronto, Toronto, Canada, 1997.

[36] D. Chabasse, "Les moisissures d'intérêt médical," Cahier $N^{\circ} 25$ de Formation de Biologie Médicale, pp. 25-27, Mycology Laboratory of Angers University Hospital, Angers, France, 2002. 
[37] J. Leslie and B. Summerell, The Fusarium Laboratory Manual, Blackwell Publishing Ltd, Oxford, UK, 1st edition, 2006.

[38] P. Dufresne, Identification des Champignons d'importance Médicale, Institut national de santé publique du Quebec, Quebec, Canada, 2018.

[39] I. C. Pimentel, C. Glienke-Blanco, J. Gabardo, R. M. Stuart, and J. L. Azevedo, "Identification and colonization of endophytic fungi from soybean (Glycine max (L.) Merril) under different environmental conditions," Brazilian Archives of Biology and Technology, vol. 49, no. 5, pp. 705-711, 2006.

[40] F. Boughachiche, S. Reghioua, L. Oulmi et al., "Isolement d'actinomycetales productrice de substance antimicrobiennes à partir de la sebkha de ain mlila," Sciences \& Technologie. C, Biotechnologies, vol. 2, no. 23, pp. 5-10, 2005.

[41] J. Sambrook and D. W. Russell, Molecular Cloning: A Laboratory Manual, Vol. 1, Cold Spring Harbor Laboratory Press, New York, NY, USA, 3rd edition, 2001.

[42] D. J. Spiegelhalter, L. S. Freedman, and M. K. B. Parmar, "Bayesian approaches to randomized trials," Journal of the Royal Statistical Society. Series A (Statistics in Society), vol. 157, no. 3, pp. 357-416, 1994.

[43] S. Lammi, "Recherche de substances à activités antimicrobiennes (antibactériennes et anticandidoses) produites par des souches levuriennes isolées des sols sahariens," Mémoire de Master en Biotechnologie Microbienne, p. 70, Université Mentouri, Constantine, Algeria, 2011.

[44] P. Powthong, B. Jantrapanukorn, A. Thongmee, and Suntornthiticharoenp, "Screening of antimicrobial activities of the endophytic fungi isolated from Sesbania grandiflora Pers," Journal of Agricultural Science and Technology, vol. 15, pp. 1513-1522, 2013.

[45] C.L.S.I (Clinical and Laboratory Standards Institute), Reference Method for Broth Dilution Antifungal Susceptibility Testing of Yeasts, Clinical and Laboratory Standards Institute, Wayn, PA, USA, 2nd edition, 2011.

[46] J. L. Fauchère and J. L. Avril, Bactériologie Générale et Médicale, Edition Ellipses, Paris, France, 2002.

[47] J. B. Harbone, Phytochimical Method: A Guide to Modern Technique of Plants, Chapman and Hall Ltd, London, UK, 3rd edition, 1998.

[48] W. C. Evans, Trease and Evans Pharmacology, WB Saunders Company Ltd., St. Louis, MO, USA, 4th edition, 2000.

[49] F. Abdel-Motaal, M. Nassar, A. El-Zayat, A. El-Sayed, and I. Ito, "Antifungal activity of endophytic fungi isolated from egyptian henbane (Hyoscyamus muticus L.)," Pakistan Journal of Botany, vol. 42, pp. 2883-2894, 2010.

[50] A. Tolulope, A. Adeleye, M. Adongbede, and T. Seriki, "Isolation and screening of endophytic fungi from three plants used in traditional medicine in Nigeria for antimicrobial activity," International Journal of Green Pharmacy, vol. 46, pp. 1678-4405, 2015.

[51] S. Mahapatra and D. Banerjee, "Diversity and screening for antimicrobial activity of endophytic fungi from Alstonia scholaris," Acta Microbiologica et Immunologica Hungarica, vol. 57, no. 3, pp. 215-223, 2010.

[52] M. Ilyas, A. Kanti, Y. Jamal, Hertina, and A. Agusta, "Biodiversity of endophytic fungi associated with Uncaria gambier roxb. (Rubiaceae) from West Sumatra," Biodiversitas, vol. 10, no. 1, pp. 23-28, 2009.

[53] J. Nourozian, R. Etebarian, and G. Khodakaramian, "Biological control of Fusarium graminearum on wheat by antagonistic bacteria," Songklanakarin Journal of Science and Technology, vol. 28, pp. 29-38, 2006.
[54] M. Harper, J. Arif, A. Ford et al., "Pestacin: a 1,3-dihydro isobenzofuran from Pestalotiopsis microspora possessing antioxidant and antimycotic activities," Tetrahedron, vol. 59, no. 14, pp. 2471-2476, 2003.

[55] R. Pimentel, G. Molina, P. Dionisio, R. Marostica, and M. Pastore, "The use of endophytes to obtain bioactive compounds and their application in biotransformation process," Biotechnology Research International, vol. 2011, Article ID 576286, 11 pages, 2011.

[56] K. Aouarib and R. Lemsara, "Etude des activités antimicrobienne et enzymatique des champignons endophytes isolés à partir d'Artemisia absinthium," Mémoire de master académique, p. 99, Faculté des Sciences de la Nature et de la Vie de l'Université Kasdi Merbah-Ouargla, Ouargla, AlgeriaFaculté des Sciences de la Nature et de la Vie de l'Université Kasdi Merbah-Ouargla, 2016.

[57] E. M. Tekwu, A. C. Pieme, and V. P. Beng, "Investigations of antimicrobial activity of some Cameroonian medicinal plant extracts against bacteria and yeast with gastrointestinal relevance," Journal of Ethnopharmacology, vol. 142, no. 1, pp. 265-273, 2012.

[58] H. Li, K. Cheng, C. Wong, K. Fan, F. Chen, and Y. Jiang, "Evaluation of antioxidant capacity and total phenolic content of different fractions of selected microalgae," Food Chemistry, vol. 102, no. 3, pp. 771-776, 2007.

[59] E. Amadi and O. Adeniyi, "Mycotoxin production by fungi isolated from stored grains," African Journal of Biotechnology, vol. 8, no. 7, pp. 1219-1221, 2009.

[60] K. Indira, N. Jayaprabha, and M. Srinivasan, "Antimicrobial activity of endophytic fungi isolated and identified from salt marsh plant in Vellar Estuary," Journal of Microbiology and Antimicrobials, vol. 7, no. 2, pp. 13-20, 2015.

[61] C. Gimenez, R. Cabrera, M. Reina, and A. González-Coloma, "Fungal endophytes and their role in plant protection," Current Organic Chemistry, vol. 11, no. 8, pp. 707-720, 2007.

[62] L. Kalhouche and L. Meziane, "Etude de quelques métabolites secondaires des souches du genre Aspergillus ayant une activité biologique," Mémoire de Master, p. 78, Faculté des Sciences de la Nature et de la Vie de l'université des Frères Mentouri Constantine, Constantine, Algeria, 2017.

[63] P. Andria, P. Kartika, F. Ahmad, W. Dewi, and I. Muhammad, "Evaluation of antibacterial and antioxidant activity of extracts of endophytic fungi isolated from Indonesian Zingiberaceous plants," Nusantara Bioscience, vol. 8, no. 2, pp. 306-311, 2016.

[64] J. Eloff, "A sensitive and quick microplate method to determine the minimal inhibitory concentration of plant extracts for bacteria," Planta Medica, vol. 64, no. 8, pp. 711-713, 1998.

[65] P. H. D. Betote, N. Nnanga, F. C. M. Benga et al., "Inhibitory effects of the essential oil and crude extracts from Greenwayodendron suaveolens (Engl. \& Diels) Verdc. subsp. suaveolens stem-barks against pneumonia bacteria," Health Sciences and Disease, vol. 22, no. 3, pp. 53-58, 2021.

[66] A. Assam, T. Yumsu, N. Moni, D. P. H. Betote, T. Fossi, and B. Penlap, "Phytochemical screening, antimycobacterial activity of three medicinal Cameroonians plants and acute toxicity of hydroethanolic extract of Vitellaria paradoxa," Journal of Drug Delivery and Therapeutics, vol. 10, no. 1-s, pp. 96-104, 2020.

[67] A. Z. Akono, "Evaluation de l'activité anti-pneumonique in vivo des extraits d'écorce de Greenwayodendron suaveolens (Annonaceae) induite par Klebsiella pneumoniae et Pseudomonas aeruginosa," Thèse de Doctorat, p. 92, Faculté de médecine et des sciences pharmaceutiques de l'université de Douala, Douala, Cameroon, 2019. 